\title{
CITY SHAPE AND THE FRACTALITY OF STREET PATTERNS
}

\author{
Nahid Mohajeri, Paul A. Longley, Michael Batty \\ Department of Geography and Centre for Advanced Spatial Analysis, University College London, UK
}

Manuscript received: January 24, 2011

Revised version: May 16, 2012

\begin{abstract}
Mohajeri N., Longley P.A., BatTy M., City shape and the fractality of street patterns. Quaestiones Geographicae 31(2), Bogucki Wydawnictwo Naukowe, Poznań 2012, pp. 29-37. 1 table, 5 figs. DOI 10.2478/v10117-012-0016-6, ISSN 0137-477X.
\end{abstract}

ABSTRACT. This paper discusses, first, the concepts of fractals and power laws in relation to the street patterns of the city of Dundee, East Scotland and, second, the results of the measurement of 6,004 street segments in the city. The trends of the street segments are presented through rose diagrams and show that there are two main street trends in the city: one is parallel with the coast, the other is roughly perpendicular to the coast. It is clear that the coastline largely regulates the street trend, because both the main street trends change along the city so as to be nearly coast-perpendicular and coast-parallel everywhere. The lengths of the street segments follow power laws. When presented on log-log plots, however, the result is not a single straight line but two straight lines. At the break in line slope, the fractal dimension changes from 0.88 to 2.20. The change occurs at the step length of about $100 \mathrm{~m}$, indicating that the short streets belong to a population that is different from that of the longer streets.

KEY WORDS: fractal, street network, city

Nahid Mohajeri, Paul A. Longley, Michael Batty, Department of Geography and Centre for Advanced Spatial Analysis, University College London, 1-19 Torrington Place, Gower Street, London WC1E 7HB, UK; e-mail: nahid.mohajeri.09@ucl. ac.uk, plongley@geog.ucl.ac.uk,M.Batty@ucl.ac.uk

\section{Introduction}

Fractals are commonly used to describe the complexity of natural patterns. They do not only describe the underlying order of natural patterns, but also many man-made and human phenomena, such as cities. Fractal theory makes it possible to advance our knowledge about the future of dynamic complex systems, such as cities, and also enables urban systems to be modelled as regards growth processes. Since a city is a complex system with a complex shape, this theory can be used to develop a better understanding of urban systems, in particular as regards geometric complexities and urban morphology.

The complex geometric patterns of many cities have been subject to intensive studies in recent decades, as they offer a way of understanding the evolution of cities, using a variety of techniques. Among the best known techniques for analysing city structures and their functionality are the concepts of fractals and complexity (Batty \& Longley 1994, Ratajczak 1998, Batty 2005). These concepts are well known and useful in analysing certain geometric patterns, particularly as regards connectivity and integration of spaces in cities.

After a brief review of the city geometry, we mainly focus here on street patterns so as to quantify the variations of street patterns within cities, in particular those cities that have been affected by different landscape constraints (valleys, rivers, the sea, mountains). By using the fractal analysis, we show here that, as regards length, street patterns have fractal characteristics and follow power-law relations. We also show that, as regards trend, the street patterns reflect the over- 


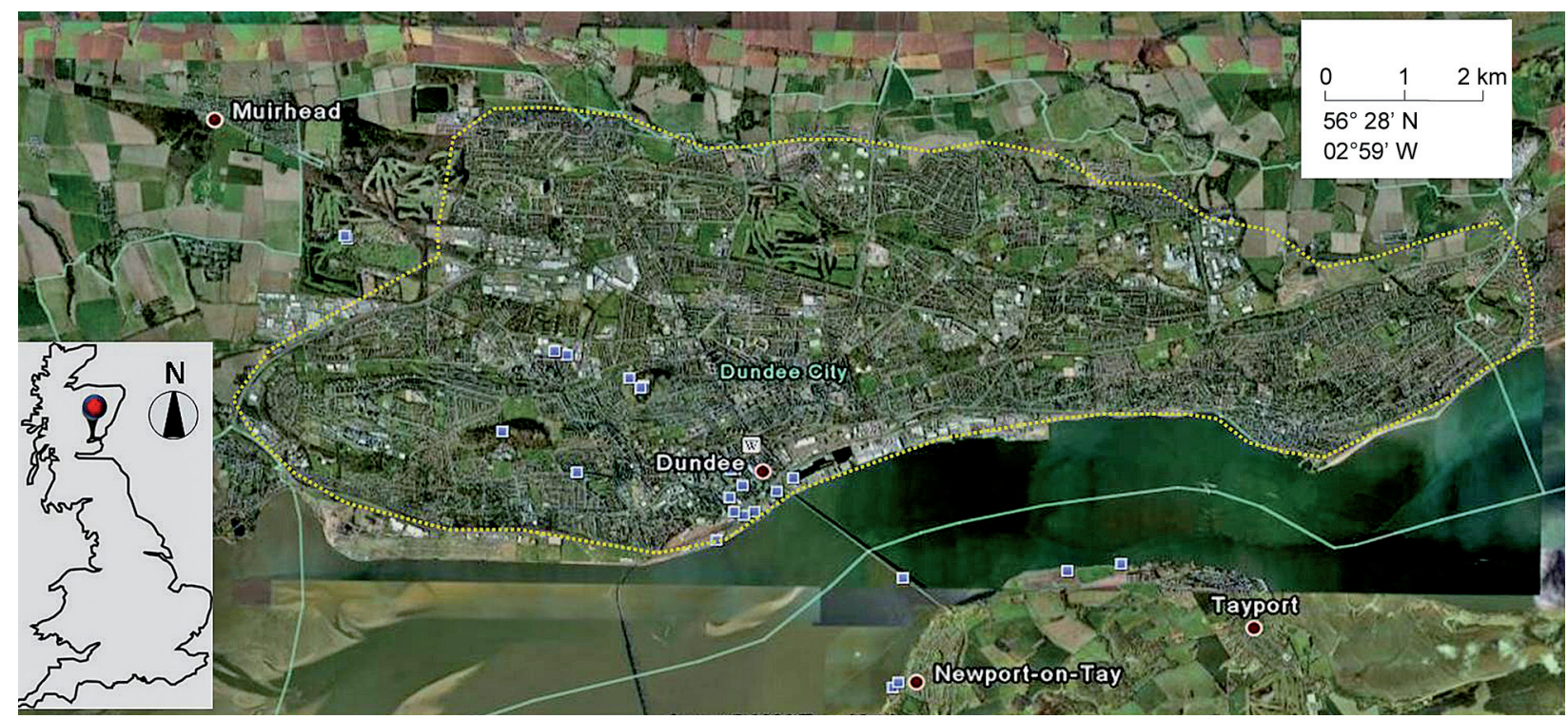

Fig. 1. Location and overview of the city of Dundee, East Scotland. The city has an overall shape crudely similar to that of half an ellipse, where the major axis coincides with the northern coastline of the Firth of Tay. The longitude and latitude of the city are also given.

Source: Google Earth.

all city shape and external landscape constraints, such as the sea (the coastline). The main focus is on the street patterns in the city of Dundee, East Scotland (Fig. 1), which has crudely a semi-elliptical boundary, part of which is determined by the coastline (a landscape boundary).

\section{Background}

\subsection{City geometry: from the organic (natural) to planned geometry of cities}

Table 1 presents several characteristics of a city geometry, from the rectangular and regular patterns, to the organic, and finally to the new geometries. According to these categories, the morphology of many old cities seems to have a very complex structure, which is manifest in characteristics such as the complex borders, intricate street networks, the characteristic distribution of functions, and the connectivity between different parts of the city (Batty \& Longley 1994, Bovill 1996, Hillier 1999, Alexander 2000, Salingaros 2003, 2005, Wolfgang 2003). The geometries of these cities show that not only at the macro-scale are there underlying patterns, but also at the micro-scale. The cities have developed gradually and organised their structures, which has affected parts at the macro-scales. Thus, the whole structure of a typical city has been developed gradually with a high level of connectivity between different parts from the bottom up and from small to large scale.

Batty \& Longley (1994) suggested a new geometry of city that arises out of interconnections and hierarchical principles. This geometry is looking for a deep meaning of spatial ordering in the city so as to organise the spatial structure efficiently, whereas the rectangular geometry hardly ever links cities to the process of evolution. Thus, according to the new geometry, which is the geometry of connectivity, interactions, and hierarchy, cities tend to be complex and disordered; however, there is a hidden order behind this irregularity. This new geometry does not try to describe the shape of cities but rather tries to provide the link between form and function; and also form and process. Batty \& Longley (1994) proposed that the new geometry of cities is the geometry of form, the geometry of order at different scales, and the geometry of hierarchy and connectivity.

\subsection{The emergence of complexity in cities}

The recognition of the city as a complex system was first made by Jacob (1961). She likened the city to a living organism with a complex be- 
Table 1. A comparison between different characteristics of city geometry, from the pure and rectangular to the organic and new geometry of cities

\begin{tabular}{|c|c|c|}
\hline \multicolumn{3}{|c|}{ Characteristics of different city geometries } \\
\hline Pure and rectangular geometry & Organic geometry & New geometry, fractal geometry \\
\hline Planned and designed cities & Unselfconscious and intuitive design & $\begin{array}{c}\text { Design of complex dynamic cities } \\
\text { using modelling }\end{array}$ \\
\hline Fast and regular growth & Irregular and slow growth & $\begin{array}{c}\text { Hierarchical and complex configura- } \\
\text { tion }\end{array}$ \\
\hline $\begin{array}{l}\text { Rapid and geographically extensive } \\
\text { change in city structure }\end{array}$ & $\begin{array}{l}\text { Incremental change in city structure } \\
\text { over long time periods }\end{array}$ & $\begin{array}{l}\text { From bottom up across a range of } \\
\text { scales }\end{array}$ \\
\hline $\begin{array}{c}\text { Control of development by few } \\
\text { decision-makers }\end{array}$ & Residents decide by trial and error & $\begin{array}{l}\text { Local residents, city experts and } \\
\text { politicians }\end{array}$ \\
\hline $\begin{array}{l}\text { Process of urban development with- } \\
\text { out dissolution }\end{array}$ & Development and dissolution & $\begin{array}{l}\text { Dynamic and complex approach to } \\
\text { city development }\end{array}$ \\
\hline Rectangular and regular patterns & Organic patterns & Underlying and complex patterns \\
\hline $\begin{array}{l}\text { Development without considering } \\
\text { neighbouring regions }\end{array}$ & $\begin{array}{l}\text { Co-evolution and interaction with } \\
\text { surroundings }\end{array}$ & Sustainable development \\
\hline
\end{tabular}

haviour, and which is potentially able to evolve in a coherent and consistent way. One common feature of cities, which is an indication of a living city, is thus organised complexity (Jacob 1961). This is resonant of an earlier notion of biological analogy to understand city growth, initiated by Geddes (1915). Further developments in this direction, particularly as regards city planning, were made by Alexander (1964). In recent decades developments in this field have used results from complexity theory (Batty \& Longley 1994, Batty 2005). Alexander (1964) suggests that organic city growth is the product of unselfconscious design. With the emphasis on form and context, and their relationship, he argues that cities are adaptive syntheses of many actions.

Batty \& Longley (1994) show how the development and use of fractal geometry is useful for understanding the physical form of cities. Fractal geometry enables cities to be simulated through computer graphics and also helps us to explain how the structures of cities evolve. At first glance they may appear irregular, but when understood in terms of fractals, they reveal a complex and diverse underlying order.

\subsection{Fractal definition}

Fractals are irregular shapes with geometries that are scale-invariant. At every scale, the degree of irregularity which characterises the geometry appears to be the same, this being referred to as self-similarity. Coastlines are appropriate exam- ples of self-similarity: the length of a rocky coastline is obtained using a measuring rod of a specified length. The length of coastline increases, because of scale invariance, as the length of measuring rod decreases according to a power law (Turcotte 1997). The power exponent determines the fractal dimension of the coastline. However, it was Richardson (1961) who was the first to formalise the phenomenon of scale-dependent length, and later on Mandelbrot (1967) reconceptualised it as fractal geometry. Since fractal geometry is the study of form and structure of rough and irregular phenomena, three related principles of self-similarity, scale invariance and power-law relations help us to understand if the geometric patterns of certain phenomena follow fractal (Brown \& Liebovitch 2010).

\subsection{Self-similarity, scale invariance, and power-law relations}

A self-similar object is composed of copies of itself at every scale and it looks similar at every scale of observation. The word 'similar' carries a geometric meaning: objects that have the same form but may be different in size (Batty \& Longley 1994, Bovill 1996, Wolfgang 2003, Brown \& Liebovitch 2010). Branching structures such as trees, in which the construction process repeats itself at each scale, are amongst the best examples of fractal structures. Small branches have essentially the same structure as large branches, except for differences in size. Therefore they are self-similar 
because the statistics of the small branches copy those of large branches.

An object is scale-invariant when it has the same characteristics at every scale of observation. As a result, if you zoom in on a fractal object observing it at ever-increasing magnification, it still looks the same (Brown \& Liebovitch 2010).

Power-law distributions are very common in artificial ('man-made') and natural phenomena. The populations of cities, the sizes (intensities) of earthquakes, word frequencies in literature, and the frequencies of family names all give rise to power-law distributions (e.g., Newman 2005, 2010). Power-law distributions imply that there are a large number of small events, processes, or objects of a particular type, and a small number of large events, processes, or objects of the same type. More specifically, power laws are scale free; in contrast to, say, normal (Gaussian) distributions, there are no objects (or events or processes) that are typical of the distribution as a whole (Barabási \& Bonabeau 2003). Following early pioneering studies (Zipf 1949, Stewart 1950), interest in and research on power laws have increased considerably during the last decades, with a large number of papers and many popular books being published on the topic (Turcotte 1997, Batty 2005, Sornette 2006, Newman 2005, Clauset et al. 2009, Schroeder 2009).

\subsection{Deterministic/theoretical and statistical fractals}

Since its original introduction by Mandelbrot (1967), the concept of fractals has found wide applicability, from pure mathematics to the most empirical aspects of engineering and social science. Given a deterministic fractal such as the Cantor set, Sierpinski carpet and triadic Koch island, or a statistical fractal such as a rocky coastline, a single mathematical equation is defined according to

$$
P(x)=C x^{-D}
$$

where $P(x)$ is the number or frequency of objects (in this paper, the number of streets), $C$ is a constant of proportionality, and $D$ (the minus sign is optional) is variously known as the exponent of the power law, its scaling exponent, or its fractal dimension.
The fractal dimension can be an integer, in which case it is equivalent to a Euclidean dimension. The Euclidean dimension of a point is zero, of a line is one, of a square is two, and of a cube is three. In general, the fractal dimension is not an integer but a fractional dimension; this is the origin of the term fractal (Batty \& Longley 1994, Turcotte 1997).

There are some differences between the deterministic fractals, Koch island, and statistical fractals such as a rocky coastline. While the perimeter of a Koch island is identically scale-invariant at all scales, the perimeter of a rocky coastline will be statistically different at different scales, but the differences do not allow the scale to be determined. Thus a rocky coastline is a statistical fractal. A second difference between the triadic Koch island and a rocky coastline is the range of scales over which scale invariance (fractal behaviour) extends. The Koch island has the maximum scale of the origin triangle and the minimum can be extended over an infinite range of scales. A rocky coastline has both a maximum and a minimum scale. In addition, the scale invariance of a coastline will be only approximately scale-invariant (fractal), and there will be statistical fluctuations in any measure of fractality. However, the triadic Koch island is exactly scale-invariant (fractal; see Turcotte 1997).

The term 'fractal' self-evidently denotes 'fractal dimension' in deterministic (perfectly self replicating) objects such as the Cantor set, Sierpinski carpet and triadic Koch island. However, the meaning may be less clear in statistical power-law distributions. Some statistical power-law distributions have fractal dimensions within the range of fractional dimensions, that is, $0<D<3$, but others do not (Turcotte 1997).

\section{Generation of power-law distributions}

The concept of a fractal, based on self-similarity where the shapes or geometric patterns do not change when observed at different scales, reveals itself in a power law. Power-law distributions are scale-invariant because the shape of the function is the same at every magnitude. When applied to a frequency (probability) distribution, a power 
law of the form $P(x)=C x^{-D}$ (equation 1 ) in general is a fractal distribution.

To determine whether a distribution is really power-law, the standard procedure is to plot the logarithms of the values $x$ and its probability $P(x)$, that is, $\log P(x)=\log C-D \log x$. A straight line on the log-log plot is then a general indication that it is a power law (Fig. 4). In reality, however, a straight line is hardly ever observed over the entire range of the values or sizes of $x$; there is normally a cut-off at the smallest perceivable size (Newman 2005, 2010). Thus, the distribution follows a power law only over a certain range.

For power laws based on histograms with certain bin widths or class limits, the fractal dimension depends on the chosen class limits (their widths). Also, there is commonly considerable 'noise' at the lower end (tail) of the straight line because there each class has few, sometimes no, observations, so that there are large fractional fluctuations in the counts. These problems are partly solved by using cumulative frequency distributions, that is, rank/frequency plots, rather than histograms. Instead of plotting a simple histogram of the data, we then plot the probability $P(X \geq x)$ that the value of the variable $X$ (for example, the length of fractures or streets) is greater than or equal to $x$ :

$$
P(X \geq x)=\int_{x}^{\infty} p\left(x^{\prime}\right) d x^{\prime}
$$

If the cumulative distribution follows a power law $P(x)=C x^{-D}$, then:

$$
P(X \geq x)=\int_{x}^{\infty} x^{\prime-D} d x^{\prime}=\frac{C}{D-1} x^{-(D-1)}
$$

The main difference between power laws based on histograms and those based on cumulative plots is that cumulative plots have shallower slopes since their exponents have values that are one less than the values of the exponents in power laws based on histograms (Section 6).

\section{Methods of street measurement}

To obtain quantitative data on street lengths and trends, we use Dundee, an old city with a current population of about 150,000 , located along the north coast of a fjord named Firth of Tay in East Scotland (Fig. 1). This city was selected for several reasons. One is that it has clear boundaries. A second reason is that the overall shape of the city is partly controlled by external constraints, primarily the coastline of the Firth of Tay. A third reason is the availability of GIS datasets, making it possible to carry out a detailed analysis of the street network of the city. A fourth reason is that the settlement has existed at least from medieval times, and is historically and morphologically interesting. In particular, it is potentially possible, in a future extension of the present work, to compare the medieval part of the city with its more recent parts. The focus here is on the lengths and trends (orientation or azimuth) of street segments. A street segment is normally just a part of a named street and is defined as the distance from one junction to the next one.

In this paper, the main method for analysing the trend in street patterns is directional analysis. Directional analysis, which primarily deals with the analysis of lineaments, identifies the directional trend of patterns. We can either use full rose diagrams or half (180 degrees) for the ease of visualisation and clarity of presentation (Fig. 2 ). Rose diagrams are very simple (Smith et al. 2009). They simply show the trend of either a certain process, like wind direction, or the trend of certain lineaments, like streets, such as we analyse in this paper.

When analysing lineament trends, there are two types of data: directional and oriented. In directional data we can distinguish one end of a lineament from the other, or left from right, such as in the flow in a river or a prevailing wind direction. Oriented data, by contrast, relate to phenomena without a directional distinction, such as streets in a city (Swan \& Sandilands 1995). Thus, if the data are directional, then the rose diagram shows a unidirectional or asymmetric trend distribution; if the data are oriented, the rose diagram shows a bidirectional or symmetrical trend distribution. For directional data the measured data azimuths range from 0 to $360^{\circ}$. For oriented data, however, the opposite directions, $180^{\circ}$ apart, are equivalent. Thus, for oriented data the graphical portrayal should either be restricted to half of a complete circle, or have a rotational symmetry, so that opposite classes or sectors in the rose have the same frequency (Swan \& Sandilands 1995). In this paper, the data presented are oriented (streets), so that the rose diagrams show 


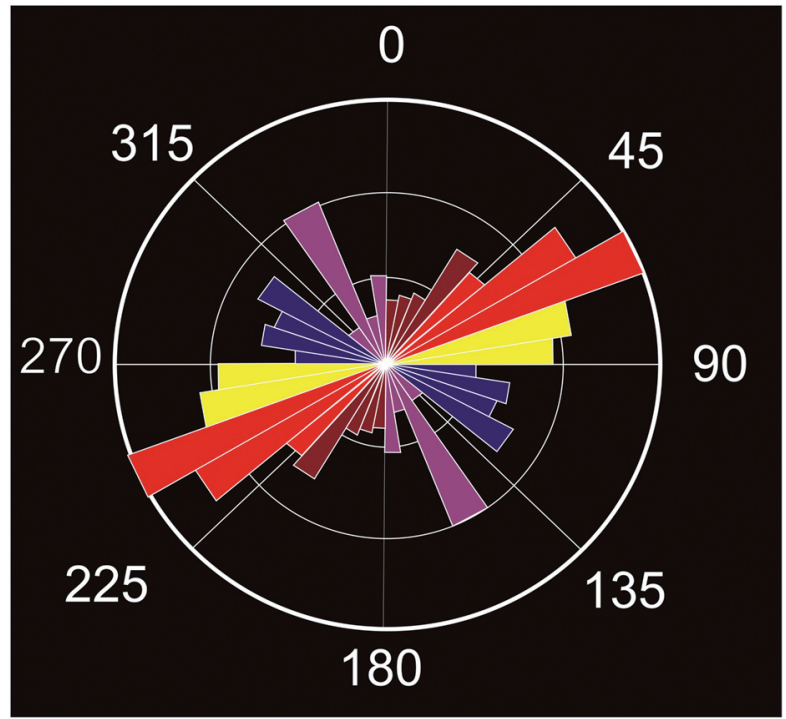

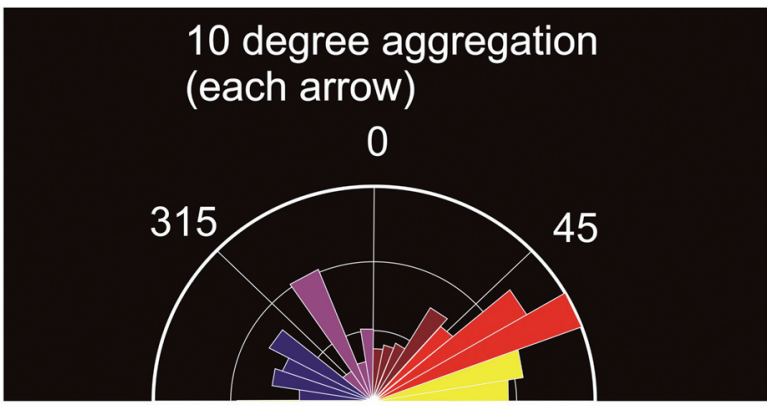

$\begin{array}{lllllll}15 & 10 & 5 & 0 & 5 & 10 & 15\end{array}$

$\%$ of total number (scale interval $5 \%$ )

Fig. 2. A simple rose diagram showing the frequencies of lineaments with different trends: we show a full rose (left) and a half (northern 180-degrees) rose diagram (right).

Source: Google.

a bidirectional or symmetric trend distribution on a half circle (0-180 degrees).

We make statistical analysis to measure the variation in street lengths. We use standard regression methods for calculating the power laws in ordinary plots as well as in log-log plots. The Gaussian distribution is used to show the distribution of orientation of patterns, and cumulative distributions (equations 2, 3) are used to show the power-law properties of street lengths. From the slope of the straight lines on the log-log plots, we calculate the exponents or fractal dimensions of the power laws.

\section{Variation in street-segment trends within Dundee}

We analyse the street trends from Dundee through GIS, using rose diagrams for visualisation. Here we focus on the margin of the city along the coast so as to present the street trends (Fig. 3). The trends are shown by rose diagrams, each of which depicts the orientation of street segments within a 500-m-radius circle using 10-degree aggregations (classes). We consider for each circle (subset) a certain number of data between 500700 , a total of 6,004 street segments, and $0-180^{\circ}$ azimuth, and then plot the trends of the main segments within the circle. We choose the subsets according to three criteria: (1) the number of streets should be similar in all the sub-areas (for each subset, the average number of measured streetsegments is 600); (2) all the sub-areas should be of a similar size; and (3) the subsets should reflect the changes in trend of the coastline.

Thus, there are obviously two main trends, north-south and roughly east-west along the coast, which is gradually changing. The northsouth trend is coast-perpendicular, the east-west trend coast-parallel. It is clear that the coastline determines the trend of the coast-parallel streets; in particular, when the coastline changes to more north-east or east-northeast, then one of the street trends follows that and changes the direction. For example, the coastline and the coast-parallel street segments become east-northeast trending towards the eastern part of the city (Fig. 3). At the same time, the northerly trending streets remain orthogonal. There are also very significant changes at the lateral ends of the city (Fig. 3, rose 1 and 10) as well as in the city centre (rose 5), where the street trend changes from two main orthogonal trends towards much more uniform trend variations. This change in trend towards the lateral (east-west) ends of the city is partly attributable to many streets in these parts being roughly perpendicular to the curved boundary of the city at these localities. The change in trend towards the city centre is presumably because this is the oldest part, where the city originated and where the segments tend to be more irregular. These results 


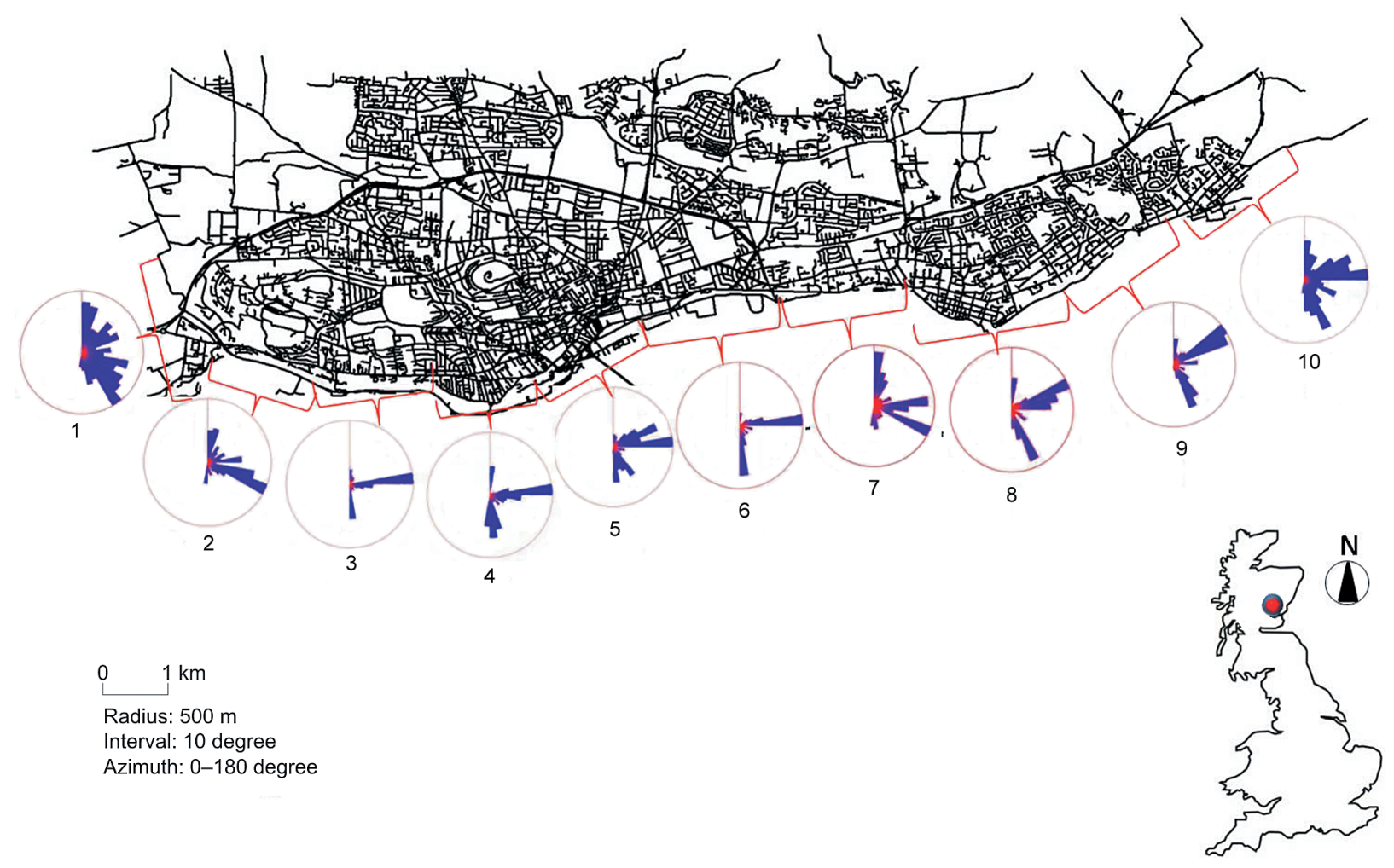

Fig. 3. Trend distribution of street patterns along the coast in Dundee (using rose diagram for visualisation)

show the coastal effects or landscape constraints on the street patterns of Dundee, which are thus very clear as regards two factors. First, one of the two dominating street trends coincides with the coastline of the Firth of Tay. This street trend follows the coastline very closely and is clearly controlled by it as a landscape factor. Second, the overall shape of the city is largely controlled by the coastline, which has acted as a major landscape factor or external constraint on the city shape.

\section{Variation in street-segment lengths within Dundee}

The frequency distribution of the lengths of all the measured streets in Dundee is shown in Fig. 4a. For the 6,004 street segments the minimum length is $3 \mathrm{~m}$ and the maximum 2,249 m. The street segments show general power-law frequency distributions, in accordance with equation 1 . To test how well the data actually follow power laws, we made log-log plots of the data. The results (Fig. 4b) show that the power laws extend over considerable ranges, but that there are cut-offs at certain critical street lengths below which the linear trend on the log-log plot (the power law) is not followed.

The length distribution (Fig. 4a) for street segments approximates a power law. When presented on log-log plots (Fig. 4b), however, the length distributions do not fit well with single straight lines over the entire length ranges. In fact, the deviations from the straight line are so large as to indicate that the data may follow different power laws within different length ranges. To test this idea, we made log-log plots where two straight lines were fitted to the data. The results (Fig. 5) give much better fits than a single power law (Fig. 4b) and suggest that the street lengths follow power laws that have different slopes, fractal dimensions, for different street-length ranges.

Therefore, the power law shows that: (i) Short streets are very common whereas long streets are rare. (ii) Street-length distributions are scalefree. This property means that there is no typical length value. (iii) The break in the slopes of the straight lines on the log-log plots of the streets may refer to different street populations as regards their function (Fig. 5). The street segments show a change in the slope of the straight line on 


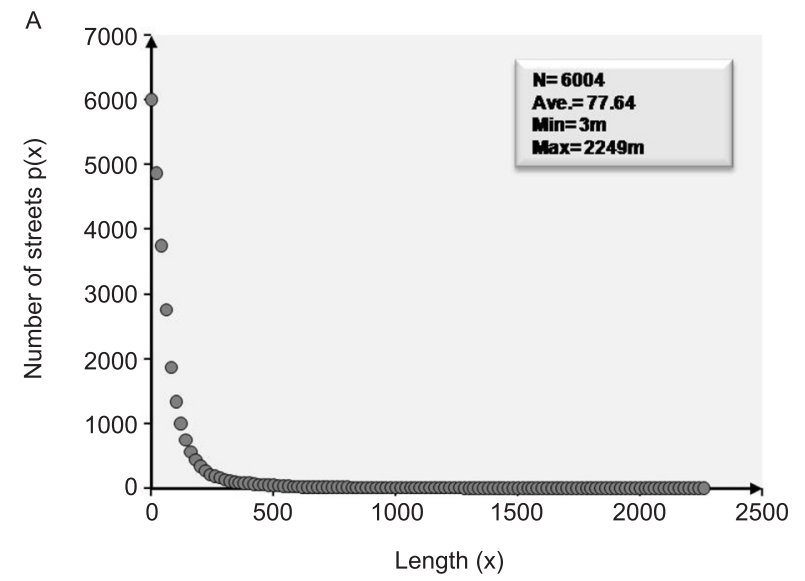

Fig. 4a. Power-law frequency plot of all street-segment lengths $(6,004)$ measured in Dundee.

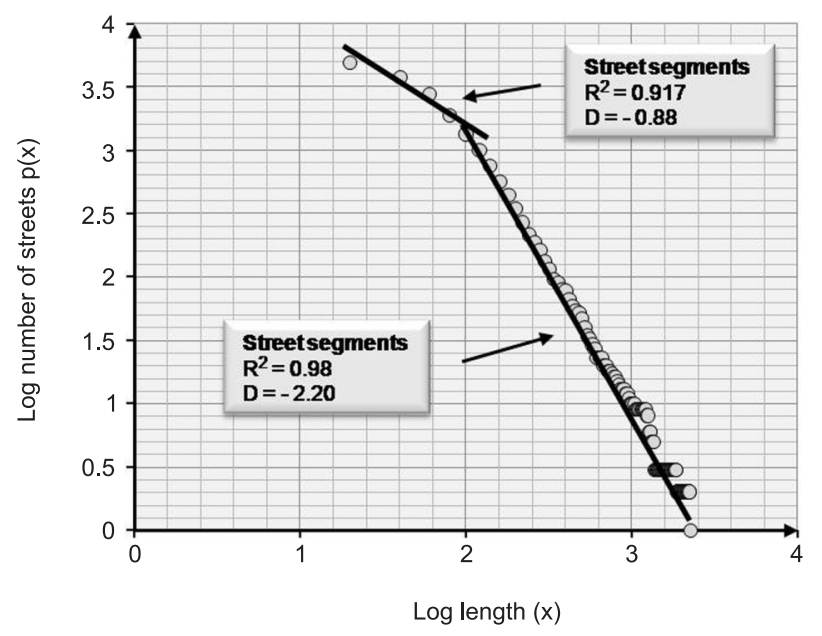

Fig. 5. Log-log plot of the length distributions of the segments selected in Fig. 4, but fitted to two straight lines. The different slopes of the fitted straight lines imply different fractal dimensions and different street populations.

the log-log plot at a length of about $100 \mathrm{~m}$. Segments that are shorter than about $100 \mathrm{~m}$ have a much shallower straight-line slope than those that exceed this length. It is clear that there is a break, and the slopes of the lines and their fractal dimensions change from 0.88 to 2.20 .

\section{Results and conclusions}

Power-law frequency distributions have received much attention in recent decades in a variety of scientific fields. This follows partly because power laws are very common in many natural

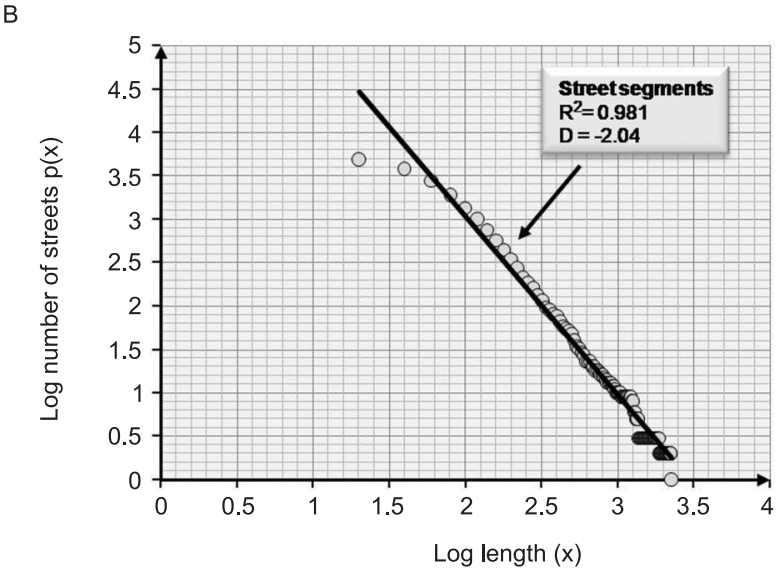

Fig. 4b. Log-log plot of the length distributions of the segments which clearly shows that the data set does not fit well with a single straight line.

and man-made processes and structures. Power laws represent scale-free frequency distributions, whereby there are no typical values in the distribution. This is in contrast to normal distributions, where the most common values, the mean value, may be regarded as typical of the distribution. When applied to the length distributions of streets, being scale-free means that there is no typical lineament length. For example, the calculated average lengths of the street lineaments discussed in the paper are certainly not typical in the sense of being the most frequent lengths. This is in contrast to normal distributions, where the typical values are the mean values.

The paper presents the results of trend and length measurements of a total of 6,004 street segments in the city of Dundee located in East Scotland on the coast of the Firth of Tay. The street segments show two main trends: one roughly parallel to the coast and another roughly perpendicular to it. Within each of these main trends, the mean trends for the coast-parallel streets are in the range of 80-90 degrees, and for the coastperpendicular trends, $160-170$ degrees. The main trends are thus roughly orthogonal.

The current street patterns of most cities are the result of a long-term evolution. Only rarely are they the result of a clearly laid-out plan; more commonly, the pattern is the result of interactions between various human activities (internal constraints) and natural (external) constrains, particularly landscape factors. Here, it is proposed that the street patterns in Dundee are partly determined by external landscape constraints. 


\section{References}

Alexander C., 1964. Notes on the synthesis of form. Harvard University Press, Cambridge MA.

AlexAnder C., 2000. The nature of order. Oxford University Press, New York.

Barabási A.L. \& Bonabeau E., 2003. Scale-free networks. Scientific American, 288(5): 50-59.

BatTY M., 2005. Cities and complexity. MIT Press, London.

Batty M. \& Longley P., 1994. Fractal cities: A geometry of form and function. Academic Press, London.

Bovill C., 1996. Fractal geometry in architecture and design. Birkhauser Verlag A.G., Boston.

Brown C. \& Liebovitch L., 2010. Fractal analysis. SAGE Publications, USA.

Clauset A., Chalizi R.C. \& Newman M.E.J., 2009. Power-law distributions in empirical data. SIAM Review, 51(4): 661703.

GEDDEs P., 1915. Cities in evolution: An introduction to the town planning movement and to the study of civics. Benn, London (1968 edition).

Hillier B., 1999. The hidden geometry of deformed grids. Environment and Planning, B, 26: 169-191.

Јасов J., 1961. The death and life of great American cities. Vintage Books, New York.

Mandelbrot B., 1967. How long is the coast of Britain? Statistical self-similarity and fractional dimension. Science, 156: 636-638.

MANDELBROT B., 1982. The fractal geometry of nature. W.H. Freeman and Company Press, New York.

Newman M.E.J., 2005. Power laws, Pareto distributions and Zipf's law. Contemporary Physics, 46: 323-351.
Newman M.E.J., 2010. Network: An introduction. Oxford University Press, Oxford.

RATAJCZAK W., 1998. Metodologiczne aspekty fraktalnego modelowania rzeczywistości (Methodological aspects of a fractal modelling of reality). Zakład Graficzny UAM, Poznań.

RichaRDSON L.F., 1961. The problems of contiguity: An appendix of statistics of deadly quarrels. General Systems Yearbook, 6: 139-187.

Salingaros N.A., 2003. Connecting the fractal city. University of Texas at San Antonio, USA

Salingaros N.A., 2005. Principles of urban structure. Techne Press, Amsterdam.

Schroeder M.R., 2009. Fractals, chaos, power laws. Dover, New York.

Smith M.J., Goodchild M.F. \& Longley P., 2009. Geospatial analysis: A comprehensive guide to principles, techniques and software tools. 3rd edition. Troubador Publishing Ltd., UK.

SORNETte D., 2006. Critical phenomena in natural sciences. Springer, Berlin.

SteWart J.Q., 1950. The development of social physics. American Journal of Physics, 18: 290-253.

SWAN A.R.H. \& SANDILANDS M., 1995. Introduction to geological data analysis. Blackwell, Oxford.

Turcotte D.L., 1997. Fractals and chaos in geology and geophys$i c s .2$ nd ed. Cambridge University Press, Cambridge.

WolfGANG E.L., 2003. Fractal and fractal architecture. PhD thesis, Vienna University of Technology, Vienna.

ZIPF G.K., 1949. Human behaviour and the principle of least effort: An introduction to human ecology. Addison-Wesley, Cambridge. 